\title{
Protein Identification via Surface-Induced Dissociation in an FT-ICR Mass Spectrometer and a Patchwork Sequencing Approach
}

\author{
Facundo M. Fernandez \\ School of Chemistry and Biochemistry, Georgia Institute of Technology, Atlanta, Georgia, USA
}

\author{
Vicki H. Wysocki \\ Department of Chemistry, University of Arizona, Tucson, Arizona, USA
}

\author{
Jean H. Futrell and Julia Laskin \\ Fundamental Science Directorate, Pacific Northwest National Laboratory, Richland, Washington, USA
}

\begin{abstract}
Surface-induced dissociation (SID) and collision-induced dissociation (CID) are ion activation techniques based on energetic collisions with a surface or gas molecule, respectively. One noticeable difference between CID and SID is that SID does not require a collision gas for ion activation and is, therefore, directly compatible with the high vacuum requirement of Fourier transform ion cyclotron resonance (FT-ICR) mass spectrometers. Eliminating the introduction of collision gas into the ICR cell for collisional activation dramatically shortens the acquisition time for MS/MS experiments, suggesting that SID could be utilized for high-throughput MS/MS studies in FT-ICR MS. We demonstrate for the first time the utility of SID combined with FT-ICR MS for protein identification. Tryptic digests of standard proteins were analyzed using a hybrid 6-tesla FT-ICR mass spectrometer with SID and CID capabilities. SID spectra of mass-selected singly and doubly charged peptides were obtained using a diamond-coated target mounted at the rear trapping plate of the ICR cell. The broad internal energy distribution deposited into the precursor ion following collision with the diamond surface allowed a variety of fragmentation channels to be accessed by SID. Composition and sequence qualifiers produced by SID of tryptic peptides were used to improve the statistical significance of database searches. Protein identification MASCOT scores obtained using SID were comparable or better than scores obtained using sustained off-resonance irradiation collision-induced dissociation (SORI-CID), the conventional ion activation technique in FT-ICR MS. (J Am Soc Mass Spectrom 2006, 17, 700-709) ( 2006 American Society for Mass Spectrometry
\end{abstract}

A fter the success of the genomics projects, proteomics has become a major research enterprise with the objective to study the functionality and dynamics of protein expression, the correlation between complementary genomes and proteomes, and posttranslational modifications of proteins that cannot be studied by genomics alone [1]. A major focus in proteomics is protein identification, a task that has been significantly accelerated by the advent of modern mass spectrometric technologies [2].

Fourier transform ion cyclotron resonance mass spectrometry (FT-ICR MS) provides the highest mass resolution and mass accuracy of present MS technologies and, despite its large size and relatively high purchase and maintenance cost, is now considered one of the most

Published online March 15, 2006

Address reprint requests to Dr. V. H. Wysocki, Department of Chemistry, University of Arizona, 1306 E University Blvd., Tucson, AZ 85721, USA E-mail: wysocki@email.arizona.edu, and Dr. Julia Laskin, P.O. Box 999 K8-88, Richland, WA 99352, USA. E-mail: Julia.Laskin@pnl.gov powerful techniques in proteomics research [3]. In the majority of FT-ICR MS proteomic applications, peptide ion activation is achieved by sustained off-resonance irradiation collision-induced dissociation (SORI-CID) [4]. SORI-CID results in sequential activation of the precursor ions by multiple low kinetic energy collisions with a collision gas that is pulsed into the ICR cell. The fast rise in pressure produced by the injection of this collision gas is followed by a long pump down delay (typically 2 to $5 \mathrm{~s}$ ) to enable fragment ion mass analysis, significantly slowing down the acquisition of MS/MS spectra.

In proteomic applications requiring the separation of complex peptide mixtures, FT-ICR MS is commonly coupled to capillary liquid chromatography [5]. In this scenario, the need to pump down the ICR cell after SORI-CID reduces the MS/MS spectral acquisition rate to an average of 6 spectra per min [6]. Low acquisition rate limits the number of precursor ions within a single chromatographic peak that can be analyzed using SORI-CID via data-dependent acquisition [7] and the 
number of collision energies that can be assayed per precursor ion, thus potentially limiting protein identification power. To increase the number of peptides that can be mass selected and fragmented via SORI-CID within a single chromatographic peak, several approaches have been proposed, including chromatographic peak parking $[8,9]$, the use of hybrid ion trap/FT-ICR mass analyzers [10], and multiplexed ion selection and dissociation [11, 12]. However, approaches such as peak parking decrease the overall sample throughput, whereas the addition of an ion trap mass analysis stage further complicates the FT-ICR setup. For these reasons, it seems logical to investigate the usefulness of alternative collisional ion activation methods for protein identification using FT-ICR MS.

Several gas-free ion activation methods alternative to SORI-CID used in FT-ICR MS have been recently reviewed [13-16]. Examples include electron capture dissociation $[17,18]$ and infrared multiphoton dissociation with a $\mathrm{CO}_{2}$ laser [19] or blackbody radiation [20]. Another collision-gas-free ion activation method is surface-induced dissociation (SID) [14-21, 22]. SID occurs by means of the collision of an ion with a surface at hyperthermal energies and has been implemented in many types of mass spectrometers [23], including single-stage and hybrid TOF instrument [24-26], orthogonal quadrupole configurations (Q SID Q) [27], and FT-ICR MS [28, 29]. In recent years, Laskin et al. implemented SID in a hybrid tandem-in-space FT-ICR MS that enables MS/MS of ions generated in an external source at high spectral acquisition rates (up to 180 spectra $\min ^{-1}$ ), with high trapping efficiency of fragment ions, well controlled kinetic energy of the precursor ions, and high fragmentation efficiency [30]. When combined with the appropriate protein database search strategy, this improved SID platform is an attractive starting point for the evaluation of FT-ICR SID MS for proteomics applications.

Proteomic database strategies tailored to take advantage of the unique characteristics of SID MS/MS data have not been investigated in depth. Recently, Schlosser and Lehmann [31] introduced a successful peptide sequencing method compatible with the MASCOT [32] database query frame. In their "patchwork peptide sequencing" approach, high mass resolution measurements $\left(R_{\mathrm{FWHM}}=10,000\right)$ are used to unequivocally identify low-mass fragments such as immonium, $\mathrm{y}_{1}, \mathrm{y}_{2}$, $a_{2}$, and $b_{2}$ ions. These fragments are later used as unique sequence and compositional qualifiers that are added as additional constraints to the MASCOT database query. Later, Fernandez et al. [33] reported a modified version of this patchwork approach for the identification of tryptic peptides using SID. However, the moderate mass resolution of the hybrid sector-TOF and orthogonal quadrupole spectrometers used in that work limited the overall power of the analytical approach. In addition, both quadrupole and time-of-flight implementations of SID involve a short time frame [26] (ca. tens of microseconds) between ion activation and fragment analysis, and thus mainly low mass peaks resulting from fast fragmentation pathways were observed. In contrast, long observation time of the FT-ICR MS allows us to observe both slow and fast fragmentation pathways following ion collision with a surface, which greatly improves the sequence coverage [15].

In this work, we report the successful use of SID in an FT-ICR MS combined with a patchwork-type database query scheme for protein identification. A recent study demonstrated that SID on a diamond surface results in a significantly better sequence coverage for singly protonated peptides than SORI-CID [34]. Broad energy distribution deposited into ions by collisions with a diamond surface results in efficient mixing of slow and fast fragmentation channels [35] not readily accessible by SORI-CID [36]. Fast fragmentation pathways commonly produce abundant immonium ions and other low-mass backbone fragments. These lowmass sequence-specific ions produced by SID can be identified by accurate mass measurements and used as unique sequence qualifiers for improved peptide and protein identification. The systematic use of the information offered by these fast fragment ions for proteomic database searches using FT-ICR SID spectra has not been reported. In this work, we examine for the first time the performance of SID for identification of standard proteins at different collision energies using an FT-ICR SID mass spectrometer and compare it to SORICID. Because SID does not require introduction of collision gas, we demonstrate that several collision energies can be rapidly assayed, allowing to select one that results in improved protein identification scores.

\section{Experimental and Methods}

\section{Reagents and Samples}

Horse-heart cytochrome $c$, yeast alcohol dehydrogenase, rabbit-muscle actin, iodoacetamide, and dithiothreitol (DTT) were purchased form Sigma-Aldrich (St. Louis, MO). RapiGest was purchased from Waters, Inc. (Milford, MA). Trypsin sequencing grade was purchased from Roche Applied Science (Indianapolis, IN). All digestion experiments were carried out in $50 \mathrm{mM}$ sodium bicarbonate buffer ( $\mathrm{pH}$ 8.0). Protein samples were treated with $0.1 \%$ RapiGest before DTT reduction and iodoacetamide alkylation. Trypsin digestion was initiated by addition of trypsin in an enzyme:substrate ratio of 5:100 (wt/wt). After a $15-\mathrm{h}$ incubation at $37^{\circ} \mathrm{C}$ in a water bath, the samples were treated with $\mathrm{HCl}$ to lower the $\mathrm{pH}$ to 2 . Following centrifugation, the clear digest solutions were transferred to new tubes and frozen until analyzed.

\section{SORI-CID and SID in an FT-ICR Mass Spectrometer}

SORI-CID and SID experiments were conducted on a specially-fabricated 6 T FT-ICR mass spectrometer de- 




Figure 1. Work flow of the "modified patchwork sequencing" approach.

scribed in detail elsewhere [30]. To mimic a data dependent acquisition experiment, the 4 to 6 most abundant precursor peptide ions were selected for SID and CID MS/MS analysis. Mass calibration was performed using the $m / z$ of the $\mathbf{y}_{1}$ ion and the $[\mathrm{M}+\mathrm{nH}]^{n+}$ precursor ion of standard peptides.

During these experiments, proteolytic peptide mixtures are continuously infused into the electrospray

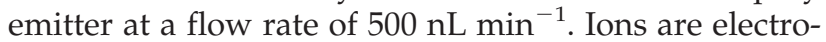
sprayed at atmospheric pressure into the end of a heated stainless steel capillary tube maintained at $150{ }^{\circ} \mathrm{C}$. Ions travel through the capillary into the vacuum system and enter an ion funnel. The ion funnel provides highly efficient ion transfer into the high vacuum region of the mass spectrometer [37]. The first quadrupole immediately following the ion funnel is used for collisional cooling of ions and their transport into the resolving quadrupole. The parent ion is massselected in a second quadrupole and accumulated in a third quadrupole held at an intermediate pressure $(2 \times$ $10^{-3}$ torr) to enhance the ion signal. The accumulation time is varied in the range $0.1-0.5 \mathrm{~s}$ depending on the abundance of the ion of interest.

Ions from the electrospray interface are extracted into an electrostatic ion guide and transferred into the ICR cell. For SORI-CID experiments, ions are trapped in the ICR cell using gated trapping in a $6 \mathrm{~V}$ potential well. Argon collision gas is pulsed into the ICR cell using a pulsed valve. Ions are radially excited slightly offresonance $(\Delta \mathrm{f}=-1000$ or $-2000 \mathrm{~Hz})$ for $400 \mathrm{~ms}$ at nearly fixed Ar pressure. The kinetic energy of the ions is incremented by changing the peak-to-peak voltage applied to the excitation plates. After a $25 \mathrm{~s}$ pumpdown delay ions are excited using a broadband chirp and detected. The long pumpdown delay used in this study was necessary because the pumping system was not optimized for SORI-CID experiments.

For SID experiments, ions are transferred through the ICR cell and collided into a surface positioned at its rear trapping plate. The collision target consists of a 2 $\mu \mathrm{m}$ thick film of carbon vapor deposited diamond on titanium disk prepared by P1 Diamond Inc. (Santa Clara, CA). The collision energy is varied by changing the DC offset applied to the ICR cell and the surface. In this work, collision energies were in the range from 25 to $140 \mathrm{eV}$. Scattered ions are captured by raising the potentials on the front and rear trapping plates of the ICR cell by 10 to $15 \mathrm{~V}$. Following $0.1 \mathrm{~s}$ delay, ions were excited by a broadband frequency chirp and detected. Ion trapping (both in the accumulation quadrupole and the ICR cell), ion excitation, and detection are controlled by a MIDAS data station [38].

\section{Modified Patchwork Peptide Sequencing}

In our modified patchwork approach, based on original work by Schlosser and Lehmann [31], accuratelydetermined sequence and compositional qualifiers are used as filters to limit the scope of the peptide sequence search and increase the confidence of peptide identification [39]. Figure 1 describes the information flow during our "patchwork-type" searches. As a first step, the ASCII fragment ion peak lists obtained at different collision energies were imported into an Excel spreadsheet along with the experimental mass-to-charge ratio of the precursor ion. Next, conditional functions within this spreadsheet were used to match the experimental peak list to the exact masses of all possible immonium, 
$\mathrm{y}_{1}$, internal dipeptide ions, and their corresponding $\mathrm{H}_{2} \mathrm{O}, \mathrm{NH}_{3}$, and $\mathrm{CO}$ losses. The largest ion in our list of possible low-mass peptide fragments for which exact masses are provided is the WW dipeptide internal ion $(373.16 \mathrm{u})$. Identification of heavier ions or ions of relative abundance below 3\% was not pursued. No variable modifications (such as phorphorylation, etc.) were introduced in this fragment ion list. Immonium, internal fragments, and $\mathrm{y}_{1}$ ions were identified by comparison with the list of possible low-mass fragments using a $\pm 0.005 \mathrm{u}$ window. Immonium ion signals unambiguously indicate the presence of the corresponding amino acids in the peptide and were utilized as compositional qualifiers. In general, L/I, V, F, Y, H, $\mathrm{P}$, and $\mathrm{W}$ residues gave rise to abundant immonium ions. The C-terminal residue of a given tryptic peptide sequence was assigned based on the identification of $\mathrm{R}$ or $\mathrm{K}$ terminal $\mathrm{y}_{1}$ ions. Following identification of the $\mathrm{y}_{1}$ ion, the $y_{2}$ ion is identified from the appropriate set of dipeptide combinations that contain the $\mathrm{y}_{1}$ residue.

Because amino acid sequence or composition information, if present, is treated by MASCOT as a rigorous filter on the candidate sequences, we chose a fairly conservative and redundant set of rules to decide if an ion should or should not be used as a sequence qualifier. Choosing the wrong qualifier prevents, in all cases, the correct identification of a peptide. Following this approach, internal $b$ ions $\left(b_{2, i}\right)$ were included in the list of qualifiers only if they fell within $\pm 0.005 \mathrm{u}$ of their expected masses, and if both the $b_{2, i}$ and the $a_{2, i}$ fragment ion peaks were simultaneously present in the spectrum. In some cases, when a $b_{2, i}$ ion was identified but the corresponding $a_{2, i}$ ion was absent, this $b_{2, i}$ ion was included as a sequence qualifier only if either of the two corresponding immonium ions was present.

For singly charged peptides, abundant internal dipeptide ions corresponding to selective cleavages [40] C-terminal to D or E were added to the qualifiers list if their experimental masses fell within a $\pm 0.010 \mathrm{u}$ tolerance interval, even in the absence of any of the corresponding immonium ions. In a few cases, the first two $\mathrm{N}$-terminal residues in a given peptide sequence $\left(b_{2}\right.$ ion) could be identified by comparing the experimental fragment ion with the value obtained by subtracting the $\mathrm{b}_{2}$ ion $\mathrm{m} / \mathrm{z}$ value from the singly protonated precursor ion mass value and adding the exact mass of an ionizing proton $(1.007,825,035 \mathrm{u})$. The directionality of the $b_{2}$ fragment was then derived by the difference in masses between the $y_{n-2}$ and $y_{n-1}$ ions ( $n$ being the number of amino acid residues in the peptide). If $a b_{2} / y_{n-2}$ ion pair was successfully identified, this information was added as an additional N-terminal sequence qualifier. The experimental molecular weight of the precursor ion, the list of identified sequence qualifiers (when applicable), and the complete fragment ion peak list (without intensities) obtained at a given collision energy were used as input for MASCOT's sequence query (www.matrixscience.com, Figure 2).

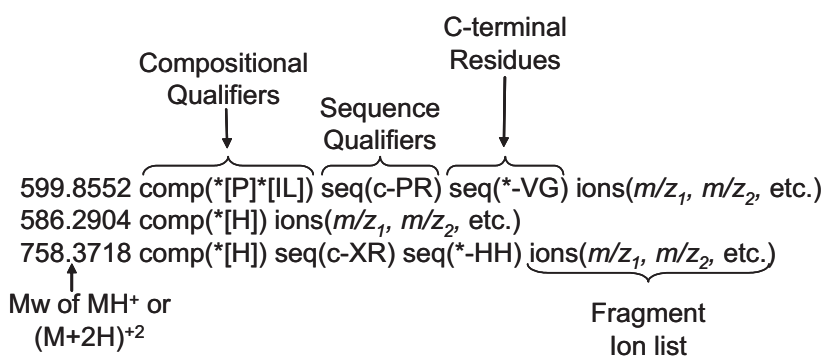

Figure 2. Example of MASCOT sequence query for actin using the modified Patchwork approach.(30, 40, and $40 \mathrm{eV}$ collision energy for precursor ions at $\mathrm{m} / \mathrm{z}=599.8552, \mathrm{~m} / \mathrm{z}=586.2904$, and $m / z=758.3718$, respectively).

The search parameter settings for the MASCOT sequence query routine were as follows: 1 maximum missed cleavage, $0.01 \mathrm{u}$ tolerance for singly charged precursor ions, $0.015 \mathrm{u}$ tolerance for doubly charged precursor ions, and $0.01 \mathrm{u}$ for the fragment ions mass. The $\mathrm{N}$-acetyl variable modification was included in the searches, which were performed using SwissProt as the reference database (all taxonomies). Trypsin was set as the proteolytic enzyme. The database-search instrument settings chosen were MALDI TOF/TOF in the case where only singly-charged ions were detected, and ESI-4SECTOR for multiply-charged ions. These two instrumental settings were chosen because they include immonium ions and provide an adequate coverage of the ion types observed in SID of protonated peptides. Isoleucine/leucine amino acid residues were identified with an " $X$ " symbol, as required by the MASCOT syntax. C-terminal and $\mathrm{N}$-terminal sequence qualifiers were described with the "(c-zz)" and "(n-zz)" MASCOT commands, where "zz" stands for any amino acid combination found. Compositional qualifiers were specified with the " $[z]$ " MASCOT command. Internal dipeptide fragments were added to the MASCOT search with the " $\left.{ }^{*}-\mathrm{zz}\right)$ " command where no directionality information could be derived from the MS/MS data, and with the " $(\mathrm{b}-\mathrm{zz})$ " when $\mathrm{N} \rightarrow \mathrm{C}$ directionality could be inferred.

\section{Results and Discussion}

Although SID has been extensively used in studies of peptide dissociation mechanisms [14], its relative performance compared to CID in practical proteomic applications has never been studied. Pioneering work by Russell and coworkers [41, 42] with a reduced-pressure ion mobility-SID-TOF mass spectrometer has demonstrated that even under moderate mass resolution conditions $\left(R_{F W H M}=200\right)$ SID is a viable ion activation tool for protein identification.

The most probable internal energy and the width of the internal energy deposition function (EDF) for SID differ from CID, resulting in mass spectral data with unique characteristics [43]. In SID, the shape of the EDF also depends on the material used as a collision target. 

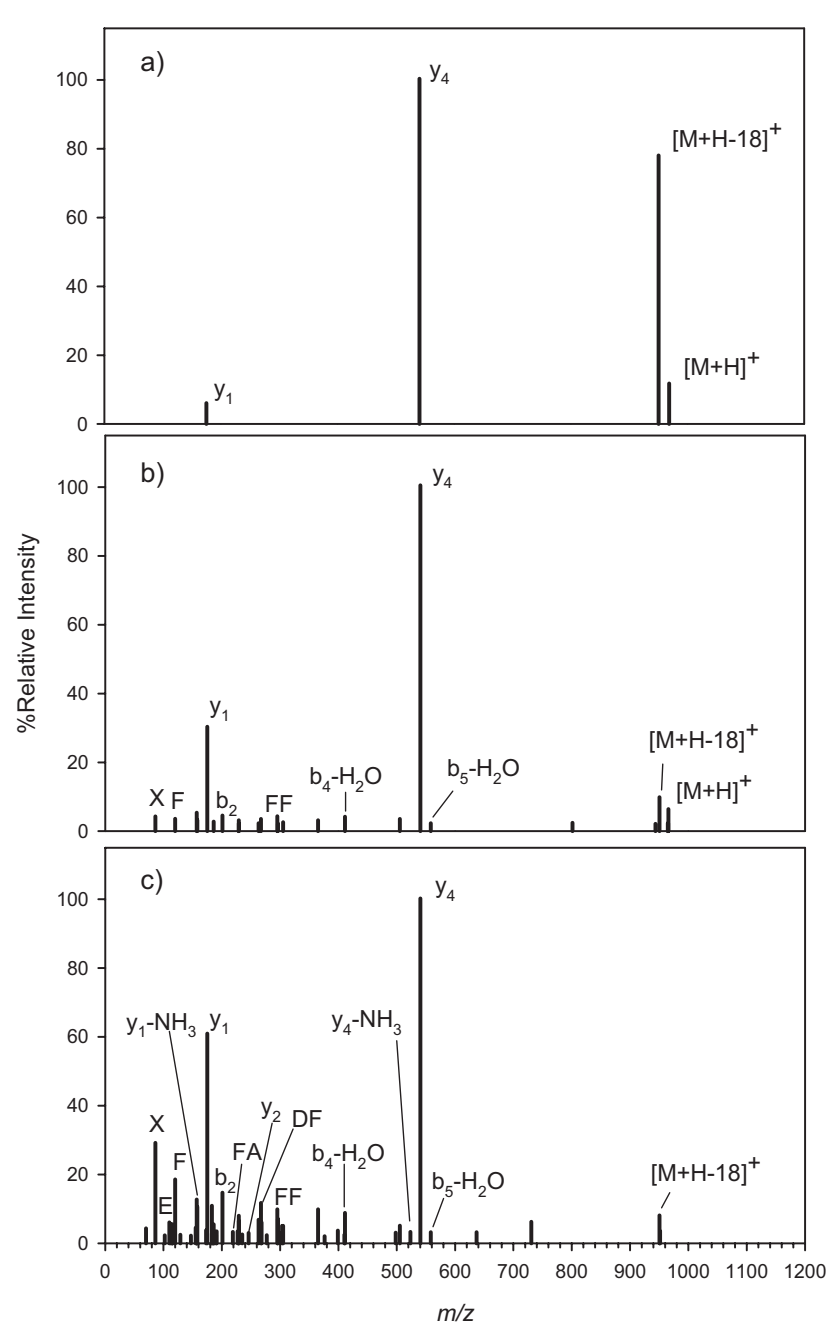

Figure 3. Typical FT-ICR surface-induced dissociation centroided spectra of the EALDFFAR (+1) ADH tryptic peptide at (a) 40 $\mathrm{eV}$, (b) $60 \mathrm{eV}$, and (c) $70 \mathrm{eV}$ collision energy. Only immonium and internal dipeptide fragment ions identified by accurate mass measurements following the patchwork sequencing set of rules have been labeled.

Laskin and Futrell have investigated the EDF width produced by collisions of singly-charged des- $\mathrm{Arg}^{1}$ bradykinin with alkyl and semi-fluorinated self assembled monolayers (SAMs), LiF, and diamond films on metal substrates [35]. This study demonstrated that the width of the EDF obtained using SAM surfaces was about 2.3 times narrower than the width of the distribution resulting from collisions with a diamond surface, at identical most-probable internal energies. Thus, collision with a diamond surface results in a better mixing of dissociation channels with different energy thresholds, allowing both slow and fast fragments to be observed in a single mass spectrum. This finding was recently used to demonstrate that SID on diamond results in a significantly improved sequence coverage for singly protonated peptides produced by MALDI [34].

Typical FT-ICR SID mass spectra of the EALDFFAR $(+1)$ and AVFPSIVGRPR $(+2)$ peptides are shown in
Figures 3 and 4, respectively. The large number of internal and immonium fragment ions identified during FT-ICR SID accurate mass spectrometric analysis is evident from these figures. The EALDFFAR spectrum (Figure 3) shows enhanced appearance of the $y_{4}$ fragment ion due to selective cleavage C-terminal to aspartic acid [44]. Table 1 summarizes the peptides identified in the ADH tryptic digest by FT-ICR SID MS in combination with the patchwork sequencing rules. The sequence and compositional qualifiers obtained at different SID collision energies are also shown in this table. The identified SIPETQK peptide was assigned to the N-terminal MSIPETQK ADH peptide with a stripped methionine amino acid residue. The TLPEIYEK peptide is most likely produced by in-source CID of the larger VVGLSTLPEIYEK tryptic peptide (ADH residues 319 to 332). Peptide ion scores and the total number of $y$ and $b$ ions identified are also shown in Table 1, and are discussed in the following section.
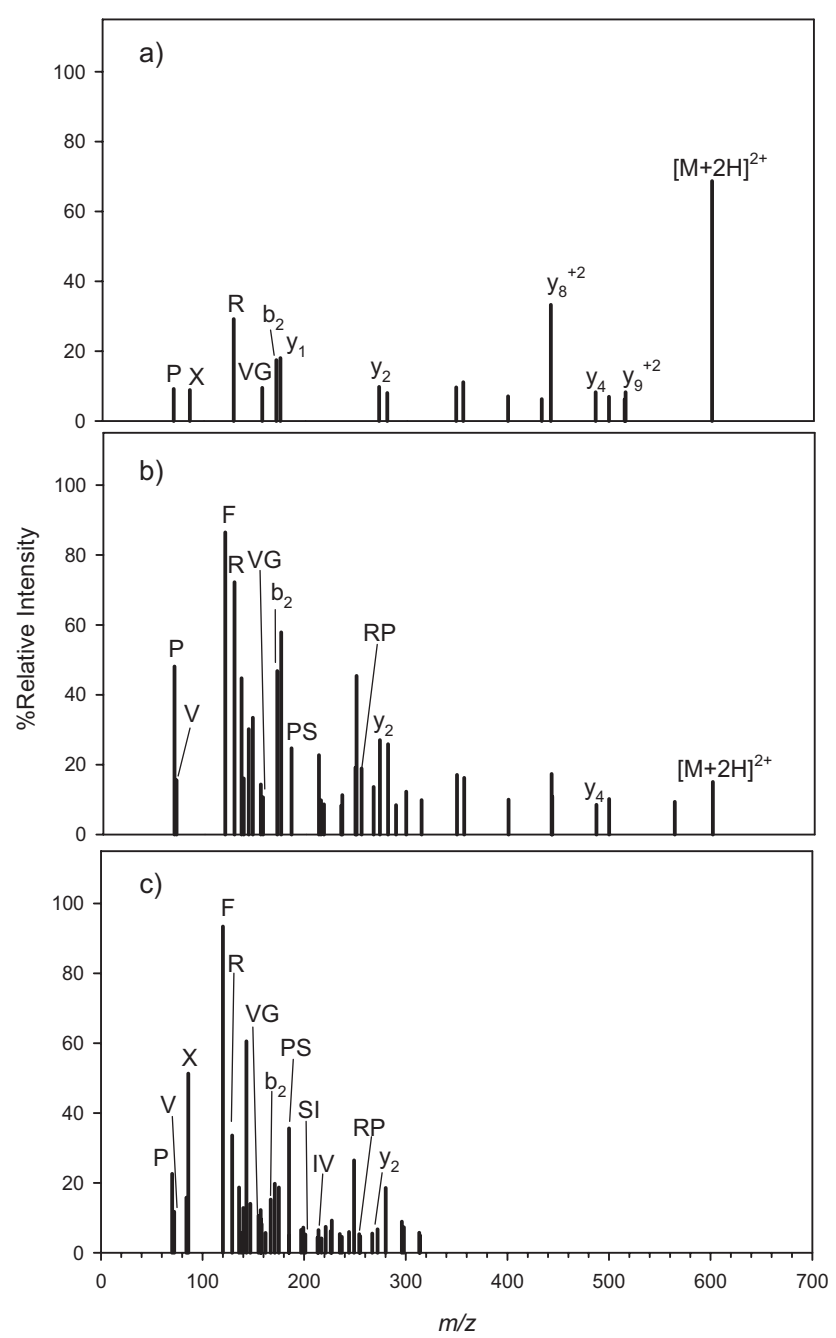

Figure 4. Typical FT-ICR surface-induced dissociation centroided spectra of the AVFPSIVGRPR (+2) Actin tryptic peptide at (a) $30 \mathrm{eV}$, (b) $60 \mathrm{eV}$, and (c) $100 \mathrm{eV}$ collision energy. Only immonium and internal dipeptide fragment ions identified by accurate mass measurements following the patchwork sequencing set of rules have been labeled. 
Table 1. Sequence and compositional qualifiers obtained at different collision energies by SID for selected peptides identified in an ADH tryptic digest

\begin{tabular}{|c|c|c|c|c|c|c|}
\hline $\begin{array}{l}\text { Protein } \\
\text { digested }\end{array}$ & $\begin{array}{c}\text { Peptide sequence } \\
\left(\mathrm{z} \text {, experimental }[\mathrm{M}+\mathrm{zH}]^{\mathrm{z}}\right)\end{array}$ & $\begin{array}{c}\text { Collision energy } \\
(\mathrm{eV})\end{array}$ & $\begin{array}{l}\text { Compositional } \\
\text { qualifiers }\end{array}$ & Sequence qualifiers ${ }^{a}$ & $\begin{array}{c}\text { Peptide } \\
\text { ion } \\
\text { score }\end{array}$ & $\Sigma\left(y_{i}+b_{i}\right)^{b}$ \\
\hline \multirow[t]{15}{*}{ ADH } & \multirow[t]{3}{*}{ DIVGAVLK $(+1,814.50)$} & 40 & none & $(\mathrm{c}-\mathrm{XK})$ & 24 & 6 \\
\hline & & 50 & $*[\mathrm{IL}], *[\mathrm{~V}]$ & $(c-X K),\left({ }^{*}-D X\right),\left({ }^{*}-V X\right)$ & 10 & 5 \\
\hline & & 60 & $*[\mathrm{IL}], *[\mathrm{~V}]$ & $(c-X K),\left(*^{*}-D X\right),\left(*^{*}-V X\right)$ & 9 & 4 \\
\hline & \multirow[t]{3}{*}{ IGDYAGIK $(+1,836.45)$} & 40 & none & $(\mathrm{c}-\mathrm{K})$ & 11 & 4 \\
\hline & & 50 & $*[\mathrm{IL}], *[\mathrm{Y}]$ & $(c-K),(*-Y A)$ & 12 & 5 \\
\hline & & 60 & $*[\mathrm{IL}], *[\mathrm{Y}]$ & $(c-K),(*-Y A),(*-D Y)$ & 13 & 5 \\
\hline & \multirow[t]{3}{*}{ SIPETOK (N-Ac) $(+1,844.44)$} & 40 & none & $(c-K),(b-P E)$ & 13 & 3 \\
\hline & & 50 & $*[I L], *[P]$ & $(c-Q K),(b-P E)$ & 10 & 4 \\
\hline & & 60 & $*[I L], *[P]$ & $(c-Q K),(b-P E)$ & 11 & 5 \\
\hline & \multirow[t]{3}{*}{ EALDFFAR $(+1,968.48)$} & 40 & none & $(c-R)$ & 14 & 2 \\
\hline & & 60 & $*[\mathrm{IL}], *[\mathrm{~F}]$ & $(c-R),(F F)$ & 9 & 3 \\
\hline & & 70 & ${ }^{*}[\mathrm{IL}],{ }^{*}[\mathrm{~F}], *[\mathrm{E}]$ & $(c-A R),(F F),\left(*^{*}-A F\right),\left({ }^{*}-D F\right)$ & 8 & 4 \\
\hline & \multirow[t]{3}{*}{ TLPEIYEK (+1,992.53) } & 40 & none & $(b-P E)$ & 12 & 3 \\
\hline & & 50 & $*[\mathrm{IL}]$ & $(c-K),(b-P E),(*-I Y),(b-Y E)$ & 17 & 4 \\
\hline & & 60 & $*[I L]$ & $\begin{array}{l}(c-E K),(b-P E),\left({ }^{*}-I Y\right),(b- \\
Y E),\left({ }^{*}-P L\right)\end{array}$ & 16 & 7 \\
\hline
\end{tabular}

${ }^{a} \mathrm{X}$ : isoleucine or leucine (I/L).

${ }^{\mathrm{b}}$ Sum of all identified $\mathrm{b}$ and $\mathrm{y}$ ions.

All the expected $\mathrm{K}$ - or R-based $\mathrm{y}_{1}$ ions were successfully identified for the peptides listed in Table 1. For most collision energies, the only immonium ions that were observed were $\mathrm{R}, \mathrm{I} / \mathrm{L}, \mathrm{V}, \mathrm{Y}, \mathrm{P}, \mathrm{F}$, a trend observed also for CID data [31]. The I/L immonium ion was particularly abundant $(100 \%$ R.I. at $60 \mathrm{eV})$ for the IGDYAGIK peptide due to the presence of two isoleucine residues in its sequence, and the fact that one of them is N-terminal, allowing for the formation of an immonium ion by a mechanism involving a protonbound complex of an aziridinone [45]. For DIVGAVLK the $y_{2}$ LK fragment ion was observed and assigned to the C-terminus, due to the additional presence of the $\mathrm{y}_{1}$ $\mathrm{K}$ ion. Although for this peptide the DX fragment ion was present the SID spectrum, the corresponding $\mathrm{y}_{6}$ ion was not observed. Consequently, the DX qualifier could not be assigned to the N-terminal $b_{2}$ ion.

The absence of collision gas in FT-ICR SID MS offers the opportunity to survey different collision energies in rapid succession and then use the individual energy spectra or composite spectra produced by summing over spectra obtained at different collision energies. Assaying several collision energies is also helpful for obtaining additional sequence qualifiers that might not be observed if only one collision energy were used to record the MS/MS spectrum. For example, for the TLPEIYEK and EALDFFAR peptides, the I/L immonium ion was detected only for collision energies above $40 \mathrm{eV}$. In the case of EALDFFAR, AF and DF sequence qualifiers were produced by increasing the collision energy from 60 to $70 \mathrm{eV}$, and the additional $\mathrm{E}$ immonium ion was observed only when the collision energy was $70 \mathrm{eV}$ or higher. For singly protonated IGDYAGIK peptide an increase in collision energy from 50 to $60 \mathrm{eV}$ resulted in detection of the additional DY sequence qualifier.
For singly-charged TLPEIYEK and SIPETQK peptides, selective fragmentation N-terminal to the proline residue was observed. This cleavage is anticipated only when a partially-mobile proton is present, as in lysine terminated peptides [46]. Subsequent C-terminal fragmentation at the glutamic acid residue of the $\mathrm{y}_{6}$ ion (for TLPEIYEK) and $\mathrm{y}_{5}$ ion (for SIPETQK) produced an abundant PE internal fragment ion (experimental $\mathrm{m} / \mathrm{z}=$ $227.1029 \mathrm{u}$, error $=0.3 \mathrm{mmu}$ ). According to its accurate mass, this dipeptide internal fragment ion could be either matched to a PE or EP fragment, but its high abundance suggests that its formation is facilitated by the enhanced $\mathrm{N}$-terminal cleavage to proline combined with enhanced C-terminal cleavage to glutamic acid. This fact identifies the ion as the PE, not the EP, fragment. The directionality information was included in the MASCOT search using the " $b-$ " prefix. In addition, The $\mathrm{y}_{2}$ ions of SIPETQK and TLPEIYEK were correctly identified at higher collision energies, adding greater selectivity to the database searches.

Table 2 shows the sequence and compositional qualifiers found for tryptic peptides obtained from actin at different collision energies. As with $\mathrm{ADH}$, all the corresponding $\mathrm{K}$ or $\mathrm{R} \mathrm{y}_{1}$ ions were successfully identified. In addition, the corresponding PR and $L R \mathrm{y}_{2}$ fragment ions were identified for AVFPSIVGRPR and IWHHTFYNELR at all collision energies. In the case of the HQGVMVGMGQK peptide fragmented at 40 and 50 $\mathrm{eV}$, the dipeptide immonium ion containing $\mathrm{Q}$ and $\mathrm{H}$ residues was found, together with the corresponding $\mathrm{y}_{9}$ ion, which indicates the presence of a terminal $b_{2}$ ion with a $\mathrm{QH}$ or $\mathrm{HQ}$ sequence. The presence of this dipeptide is confirmed by the identification of the $\mathrm{H}_{2} \mathrm{O}$ and $\mathrm{NH}_{3}$ losses. However, the directionality of this sequence tag could not be determined due to the absence of the corresponding $\mathrm{y}_{10}$ ion and, as such, it was 
Table 2. Sequence and compositional qualifiers obtained at different collision energies by SID for selected peptides identified in an Actin tryptic digest

\begin{tabular}{|c|c|c|c|c|c|c|}
\hline $\begin{array}{l}\text { Protein } \\
\text { digested }\end{array}$ & $\begin{array}{l}\text { Peptide sequence } \\
(\mathrm{z} \text {, experimental } \\
\left.[\mathrm{M}+\mathrm{zH}]^{\mathrm{z}+}\right)\end{array}$ & $\begin{array}{c}\text { Collision } \\
\text { energy }(e V)\end{array}$ & $\begin{array}{l}\text { Compositional } \\
\text { qualifiers }\end{array}$ & Sequence qualifiers & $\begin{array}{l}\text { Peptide } \\
\text { ion } \\
\text { score }\end{array}$ & $\Sigma\left(y_{i}+b_{i}\right)$ \\
\hline \multirow[t]{10}{*}{ Actin } & HQGVMVGMGQK & 40 & $*[\mathrm{H}]$ & $(c-K),(n-[\mathrm{OH}][\mathrm{QH}])$ & 22 & 6 \\
\hline & $(+2,586.29)$ & 50 & $*[\mathrm{H}]$ & $(c-K)(n-[\mathrm{QH}][\mathrm{OH}])$ & 27 & 6 \\
\hline & & 60 & $*[\mathrm{H}]$ & $(\mathrm{c}-\mathrm{K}),(*-\mathrm{OH})$ & 18 & 4 \\
\hline & AVFPSIVGRPR & 30 & $*[P], *[I L], *[R]$ & $(c-P R),\left({ }^{*}-V G\right)$ & 14 & 5 \\
\hline & $(+2,599.86)$ & 60 & $*[\mathrm{P}], *[\mathrm{~F}], *[\mathrm{~V}], *[\mathrm{R}]$ & $(c-P R),\left({ }^{*}-V G\right),\left({ }^{*}-R P\right),\left({ }^{*}-P S\right),\left({ }^{*} A V\right)$ & 8 & 3 \\
\hline & & 100 & $\begin{array}{l}*[\mathrm{P}], *[\mathrm{~F}], *[\mathrm{~V}], *[\mathrm{IL}], \\
*[\mathrm{R}]\end{array}$ & $\begin{array}{l}(\mathrm{c}-\mathrm{PR}),\left({ }^{*}-\mathrm{VG}\right),\left({ }^{*}-\mathrm{RP}\right),\left({ }^{*}-\mathrm{IV}\right),\left({ }^{*}-\mathrm{SI}\right), \\
\left({ }^{*}-\mathrm{PS}\right),\left({ }^{*}-\mathrm{AV}\right)\end{array}$ & 5 & 2 \\
\hline & IWHHTFYNELR & 40 & $*[\mathrm{H}]$ & $(\mathrm{c}-\mathrm{XR}), *[\mathrm{HH}]$ & 5 & 3 \\
\hline & $(+2,758.37)$ & 60 & $*[\mathrm{H}], *[\mathrm{IL}]$ & $(\mathrm{c}-\mathrm{XR}),\left({ }^{*}-\mathrm{HH}\right),\left({ }^{*}-\mathrm{HW}\right),\left({ }^{*}-\mathrm{HT}\right)$ & 4 & 3 \\
\hline & & 100 & $*[\mathrm{H}], *[\mathrm{IL}], *[\mathrm{Y}],\left[{ }^{*} \mathrm{~W}\right]$ & $(c-X R),\left({ }^{*}-\mathrm{HH}\right),\left({ }^{*}-\mathrm{HW}\right),\left({ }^{*}-\mathrm{HT}\right),\left({ }^{*}-\mathrm{YN}\right)$ & 4 & 2 \\
\hline & & 140 & $\begin{array}{l}*[\mathrm{H}], *[\mathrm{IL}], *[\mathrm{Y}],[* \mathrm{~W}] \\
\quad *[\mathrm{~F}]\end{array}$ & $(\mathrm{c}-\mathrm{XR}),\left({ }^{*}-\mathrm{HH}\right),\left({ }^{*}-\mathrm{HW}\right),\left({ }^{*}-\mathrm{HT}\right),\left({ }^{*}-\mathrm{YN}\right)$ & 4 & 2 \\
\hline
\end{tabular}

input into MASCOT as a potential $\mathrm{QH}$ or $\mathrm{HQ} \mathrm{N}-$ terminal sequence qualifier. At higher collision energy $(60 \mathrm{eV})$ only the QH/HQ dipeptide was observed but not the $\mathrm{y}_{9}$ or $\mathrm{y}_{10}$ ions, and this information was input without any reference to its position within the peptide chain.

For the AVFPSIVGRPR peptide, an increasing number of dipeptide fragment ions was identified as collision energy was increased. However, the number of $y$ ions that were identified simultaneously decreased, ( $\mathrm{y}_{1}$, $\mathrm{y}_{2}, \mathrm{y}_{4}, \mathrm{y}_{8}$, and $\mathrm{y}_{9}$ at $30 \mathrm{eV} ; \mathrm{y}_{1}, \mathrm{y}_{2}$, and $\mathrm{y}_{4}$ at $60 \mathrm{eV}$; and $\mathrm{y}_{1}$ and $y_{2}$ at $100 \mathrm{eV}$ ). A similar trend was observed for IWHHTFYNELR. Only one compositional qualifier was obtained at $40 \mathrm{eV}$ while five qualifiers were obtained at $140 \mathrm{eV}$. However, the number of $\mathrm{y}$ and $\mathrm{b}$ fragment ions identified decreased from 3 to 2 . Interestingly, the $\mathrm{W}$ immonium ion, not commonly observed in SID spectra, was detected at very high collision energy $(140 \mathrm{eV})$.

Table 3 shows the compositional and sequence qualifiers obtained for cytochrome $c$ tryptic peptides. Again, a variety of internal fragments and immonium ions could be identified by a combination of accurate mass measurements and the patchwork sequencing rules.

\section{Protein Identification Using FT-ICR SID Spectral Data}

In MASCOT sequence query database searches the overall protein identification score is a direct sum of the individual peptide ion scores and, thus, optimum protein identification is obtained when optimum peptide ion scores are produced. During protein searches, MASCOT matches experimental mass values to fragment or precursor ions based on a probability approach. Because probabilities encompass a large range of magnitudes, they are reported as $-10 \log (P)$, where $P$ is the absolute probability of a random match. A high score means a highly-successful match. Individual peptide ion scores obtained via MASCOT patchwork searches of FT-ICR SID MS data are shown in the fifth column of Tables 1 through 3, respectively. These peptide ion scores were calculated using all the peaks detected in the centroided mass spectrum, including the $\mathrm{y}$ and $\mathrm{b}$ ion series. Changes in collision energy had different effects on the peptide ion scores. In some cases, an increase in collision energy increased a peptide's ion score. For example, IGDYAGIK showed a score that increased with increasing collision energy because both the num-

Table 3. Sequence and compositional qualifiers obtained at different collision energies by SID for selected peptides identified in an cytochrome $c$ tryptic digest.

\begin{tabular}{|c|c|c|c|c|c|c|}
\hline $\begin{array}{l}\text { Protein } \\
\text { digested }\end{array}$ & $\begin{array}{c}\text { Peptide sequence } \\
(\mathrm{z} \text {, experimental } \\
\left.[\mathrm{M}+\mathrm{zH}]^{++}\right)\end{array}$ & $\begin{array}{c}\text { Collision } \\
\text { energy }(e V)\end{array}$ & $\begin{array}{c}\text { Compositional } \\
\text { qualifiers }\end{array}$ & Sequence qualifiers & $\begin{array}{c}\text { Peptide } \\
\text { ions } \\
\text { score }\end{array}$ & $\Sigma\left(y_{i}+b_{i}\right)$ \\
\hline \multirow[t]{8}{*}{ Cyt-c } & TGPNLHGLFGR & 50 & ${ }^{*}[\mathrm{P}]$ & $(\mathrm{c}-\mathrm{GR}),(*-\mathrm{PN})$ & 28 & 5 \\
\hline & $(+2,584.81)$ & 60 & ${ }^{*}[\mathrm{P}], *[\mathrm{H}]$ & $(\mathrm{c}-\mathrm{GR}),\left({ }^{*}-\mathrm{PN}\right),\left({ }^{*}-\mathrm{HG}\right)$ & 31 & 6 \\
\hline & GDVEK (N-Ac) & 25 & $*[\mathrm{~V}]$ & $(c-E K),\left({ }^{*}-V E\right)$ & 14 & 5 \\
\hline & $(+1,589.28)$ & 40 & ${ }^{*}[\mathrm{~V}],[\mathrm{D}],{ }^{*}[\mathrm{E}]$ & $(c-E K),\left({ }^{*}-V E\right),\left({ }^{*}-D V\right)$ & 16 & 6 \\
\hline & & 60 & ${ }^{*}[\mathrm{~V}],{ }^{*}[\mathrm{D}],{ }^{*}[\mathrm{E}]$ & $(c-K)$ & 25 & 5 \\
\hline & TGQAPGFTYTDANK & 50 & ${ }^{*}[\mathrm{Q}],{ }^{*}[\mathrm{P}]$ & $(c-K),\left({ }^{*}-Q A\right)$ & 12) & 6 \\
\hline & $(+2,735.84)$ & 60 & $*[\mathrm{Q}],{ }^{*}[\mathrm{P}]$ & $(\mathrm{c}-\mathrm{NK}),\left({ }^{*}-\mathrm{OA}\right)$ & 21 & 8 \\
\hline & & 100 & $\begin{array}{l}*[\mathrm{Q}],{ }^{*}[\mathrm{P}],{ }^{*}[\mathrm{~A}],{ }^{*}[\mathrm{~T}],{ }^{*}[\mathrm{~N}], \\
\quad *[\mathrm{~F}],{ }^{*}[\mathrm{Y}]\end{array}$ & $\begin{array}{c}(\mathrm{c}-\mathrm{NK}),\left({ }^{*}-\mathrm{TY}\right),\left({ }^{*}-\mathrm{TF}\right),\left({ }^{*}-\mathrm{TD}\right), \\
\left({ }^{*}-\mathrm{AN}\right),\left({ }^{*}-\mathrm{PG}\right),\left({ }^{*}-\mathrm{GT}\right)\end{array}$ & 4 & 8 \\
\hline
\end{tabular}


Table 4. Energy-resolved protein identification scores for database searches performed in the presence or absence of sequence and compositional qualifiers

\begin{tabular}{|c|c|c|c|c|c|c|c|c|}
\hline \multirow[b]{2}{*}{$\begin{array}{c}\text { Protein } \\
\text { tested }\end{array}$} & \multirow[b]{2}{*}{ Search no. } & \multicolumn{6}{|c|}{ Information included in MASCOT query } & \multirow[b]{2}{*}{$\begin{array}{c}\text { Protein } \\
\text { Score/Cutoff }\end{array}$} \\
\hline & & $\begin{array}{c}\text { Coll. energy } \\
\text { peptide } 1\end{array}$ & $\begin{array}{c}\text { Coll. energy } \\
\text { peptide } 2\end{array}$ & $\begin{array}{c}\text { Coll. energy } \\
\text { peptide } 3\end{array}$ & $\begin{array}{c}\text { Coll. energy } \\
\text { peptide } 4\end{array}$ & $\begin{array}{c}\text { Coll. energy } \\
\text { peptide } 5\end{array}$ & $\begin{array}{c}\text { Include } \\
\text { qualifiers } \\
?\end{array}$ & \\
\hline \multirow[t]{2}{*}{$\mathrm{ADH}$} & 1 & 40 & 60 & 40 & 40 & 50 & $\checkmark$ & $76 / 38$ \\
\hline & 2 & 40 & 60 & 40 & 40 & 50 & & $64 / 61$ \\
\hline \multirow[t]{2}{*}{ Actin } & 3 & 50 & 30 & 40 & - & - & $\checkmark$ & $49 / 24$ \\
\hline & 4 & 50 & 30 & 40 & - & - & & $49 / 34$ \\
\hline \multirow[t]{2}{*}{ Cyt-c } & 5 & 60 & 60 & 60 & - & - & $\checkmark$ & $80 / 21$ \\
\hline & 6 & 60 & 60 & 60 & - & - & & $80 / 35$ \\
\hline
\end{tabular}

ber of identified $\mathrm{b}$ and $\mathrm{y}$ ions and the number of sequence and compositional qualifiers increased with collision energy (Table 1). In other cases, such as singlycharged DIVGAVLK, it is observed that even though additional sequence qualifiers are obtained (DX and VX dipeptides) at high collision energies, the peptide ion score [32] decreases significantly with increasing collision energy, due to decrease in the number of identified $\mathrm{b}$ and $\mathrm{y}$ ions (Table 1).

In a few cases, it was noticed that, even though the number of qualifiers and the number of identified $b$ and $y$ ions increased with collision energy, the absolute peptide ion score decreased. Such is the case of SIPETQK (Table 1). Further investigation of the sequence query results showed that the expectation values obtained during the protein search for this peptide decreased from 0.15 at $40 \mathrm{eV}$ to 0.015 at $60 \mathrm{eV}$. Expectation values reflect the number of times it would be expected to obtain a similar peptide ion score purely by chance. Low expectation values mean more significant peptide ion scores. In this sense, not only the absolute value of the peptide ion score can be used as a measure of success in peptide identification but the ratio of the peptide ion score to the expectation value can also be investigated. The peptide ion score/expectation value ratio for singly-charged SIPETQK increased with increasing SID collision energy, thus revealing an improvement in identification confidence. A similar result was obtained for EALDFFAAR (Table 1).

MASCOT protein database searches of the protein tryptic digest FT-ICR SID mass spectral data were performed using the optimum collision energies for each peptide, according to the peptide ion scores observed previously. Table 4 shows protein search scores, the score cutoffs, and collision energies chosen for each peptide. The results indicate that optimized collision energies produce scores that are larger than the cutoff value, demonstrating that protein identification using FT-ICR SID MS is feasible and produces protein matches that are statistically significant. Searches 1, 3, and 5 used the full list of sequence and compositional qualifiers and the fragment ion list as previously depicted in Figure 2. The second set of protein searches (2, 4 , and 6) shows the observed identification scores obtained when the sequence and compositional qualifiers were omitted from the search. It was noted that for every protein digest, the scores decreased or the statistical significance of the results decreased (the score cutoff increased) if the qualifiers were excluded from the query. Sequence and compositional qualifiers are utilized as strict search pre-filters to reduce the number of candidate peptide sequences that can possibly match the experimental MS/MS data.

When protein searches with compositional and sequence qualifiers were conducted for the mass spectral data at a single fixed collision energy, lower protein scores were obtained. For example, searches for ADH at 40 and $60 \mathrm{eV}$ produced protein scores of 70 and 45, whereas a search combining the $40 \mathrm{eV}$ spectrum for DIVGAVLK, the $60 \mathrm{eV}$ spectrum for IGDYAGIK, the 40 $\mathrm{eV}$ spectrum for SIPETQK, the $40 \mathrm{eV}$ spectrum for EALDFFAR, and the $50 \mathrm{eV}$ spectrum for TLPEIYEK produced a score of 76 (Table 4). In the case of actin, database search using a single collision energy of $60 \mathrm{eV}$ returned a dubious match with a score of 18 and a cutoff value of 24 (mostly because the peptide HQGVMVGMGQK was not identified at this collision energy), whereas the combined search using the 50, 30, and 40 $\mathrm{eV}$ spectra produced a significant score of 49 with an identical score cutoff. For cytochrome $c$, a single collision energy $(60 \mathrm{eV})$ produced optimum protein identification scores. However, the optimum collision energy cannot be estimated a priori but can be selected only after several energies have been assayed. Russell and coworkers suggested that ramping the collision energy during SID acquisition is a viable alternative to assaying different collision energies one at a time [41].

\section{Comparison of SID and SORI-CID for Protein Identification Purposes}

SORI-CID has been utilized with great success for identification of doubly protonated tryptic peptide ions [3]. For this reason, we conducted conventional SORICID experiments for doubly protonated precursors as a benchmark for the performance of SID for protein identification. Several collision energies were assayed 
Table 5. Sequence and compositional qualifiers obtained by SORI-CID at collision energies showing maximum sequence coverage for selected peptides identified in tryptic digests of model proteins

\begin{tabular}{|c|c|c|c|c|c|}
\hline $\begin{array}{l}\text { Protein } \\
\text { digested }\end{array}$ & $\begin{array}{c}\text { Peptide sequence } \\
\text { (z, precursor ion kinetic } \\
\text { energy }[\mathrm{eV}])\end{array}$ & $\begin{array}{l}\text { Compositional } \\
\text { qualifiers }\end{array}$ & $\begin{array}{l}\text { Sequence } \\
\text { qualifiers }\end{array}$ & $\begin{array}{l}\text { Peptide } \\
\text { ion score }\end{array}$ & $\Sigma\left(y_{i}+b_{i}\right)$ \\
\hline \multirow[t]{3}{*}{ Actin } & HQGVMVGMGQK $(+2,40)$ & {$\left[{ }^{*} \mathrm{H}\right]$} & $(\mathrm{c}-\mathrm{K}), \mathrm{n}-([\mathrm{OH}][\mathrm{OH}])$ & 21 & 8 \\
\hline & AVFPSIVGRPR $(+2,67)$ & {$\left[{ }^{*} \mathrm{P}\right],\left[{ }^{*} \mathrm{~F}\right]$} & $(c-R)$ & Not found & Not found \\
\hline & IWHHTFYNELR $(+2,61)$ & {$\left[{ }^{*} \mathrm{H}\right]$} & $(c-X R),\left({ }^{*}-H H\right),\left({ }^{*}-H W\right)$ & 27 & 7 \\
\hline \multirow[t]{3}{*}{ Cyt-c } & TGPNLHGLFGR $(+2,40)$ & none & $(c-G R),(*-P N)$ & 45 & 8 \\
\hline & GDVEK (N-Ac) $(+1,15)$ & none & $(\mathrm{c}-\mathrm{K})$ & 7 & none \\
\hline & TGQAPGFTYTDANK $(+2,45)$ & {$\left[{ }^{*} \mathrm{Q}\right]$} & $(c-K),(*-Q A)$ & 8 & 5 \\
\hline
\end{tabular}

for SORI-CID, but only spectra showing maximum peptide ion scores were used for MASCOT searches.

Comparison of the best MASCOT peptide ion scores produced by SID and SORI-CID (Tables 2 and 3 for SID and Table 5 for SORI-CID) showed that for HQGVMVGMGQK, AVFPSIVGRPR, GDVEK, and TGQAPGFTYTDANK, SID was superior to SORI-CID. This effect can be attributed to the presence of a larger number of sequence and compositional qualifiers in SID spectra of these peptides compared to SORI-CID (Table 5). Conversely, SORI-CID produced higher scores for IWHHTFYNELR and TGPNLHGLFGR than SID because a larger number of $\mathrm{y}$ and $\mathrm{b}$ ions were observed in SORI-CID spectra of these peptides.

Table 6 shows protein identification scores obtained for actin and cytochrome $c$ using SORI-CID. Both proteins were correctly identified. Similarly to SID protein searches, the statistical confidence of the protein identification scores decreased if sequence qualifiers were not incorporated into the MASCOT search. The performance of SID and SORI-CID towards protein identification can be compared from Tables 4 and 6 . Protein identification scores for cytochrome $c$ obtained using SID were significantly higher than the scores obtained using SORI-CID. The lower degree of success of SORICID can be attributed to much lower peptide ion scores obtained for GDVEK and TGQAPGFTYDANK, as shown in Table 5 . In the case of actin, almost identical protein scores were obtained by SID and SORI-CID. ADH could only be identified via SID, but not by SORI-CID, probably because of the insufficient fragmentation efficiency of singly-charged peptides by the SORI-CID activation method.

Table 6. Protein identification scores for database searches performed using SORI-CID spectral information

\begin{tabular}{|c|c|c|c|c|c|}
\hline \multirow[b]{2}{*}{$\begin{array}{l}\text { Protein } \\
\text { tested }\end{array}$} & \multirow[b]{2}{*}{$\begin{array}{c}\text { Search } \\
\text { no. }\end{array}$} & \multicolumn{3}{|c|}{$\begin{array}{l}\text { Information included } \\
\text { in MASCOT query }\end{array}$} & \multirow[b]{2}{*}{$\begin{array}{c}\text { Protein } \\
\text { score/cutoff }\end{array}$} \\
\hline & & $\begin{array}{c}+1 \\
\text { lons }\end{array}$ & $\begin{array}{c}+2 \\
\text { lons }\end{array}$ & $\begin{array}{c}\text { Sequence and } \\
\text { compositional } \\
\text { qualifiers }\end{array}$ & \\
\hline \multirow[t]{2}{*}{ Actin } & & & $\checkmark$ & $\checkmark$ & $50 / 24$ \\
\hline & & & $\checkmark$ & & $50 / 34$ \\
\hline \multirow[t]{2}{*}{ Cyt-c } & & $\checkmark$ & $\checkmark$ & $\checkmark$ & $62 / 31$ \\
\hline & & $\checkmark$ & $\checkmark$ & & $62 / 35$ \\
\hline
\end{tabular}

\section{Conclusions}

This paper demonstrates that protein sequencing using SID in an FT-ICR MS and a modified patchwork approach is a viable alternative to bottom up sequencing using SORI-CID. SID produced a larger number of low-mass fragments ions that were used as unique sequence qualifiers for MASCOT database searches. Addition of partial sequence qualifiers constrains database searches, effectively filters out many potential candidate sequences, and thereby increases the statistical confidence levels of the results. SORI-CID spectra showed fewer immonium ions than SID and, thus, a smaller number of compositional qualifiers could be derived from them. SORI-CID of doubly protonated tryptic peptides in many cases produced larger $y$ and $b$ fragments not observed in SID spectra. However, for the proteins examined in this work, identification scores obtained using SID were similar or better than the scores obtained using SORI-CID. A salient feature of the FT-ICR SID approach is that the absence of a collision gas allows sequential assay of several collision energies for each investigated peptide, one of which can be selected to produce optimum peptide ion scores, leading to improved protein identification. Singly charged ions not easily activated by SORI-CID under normal circumstances were effectively activated by SID, which makes the FT-ICR SID MS patchwork approach attractive not only for FT-ICR mass spectrometers equipped with an electrospray source but also for ion activation in MALDI FT-ICR MS.

\section{Acknowledgments}

The experimental work described in the paper was performed during a visit of FMF to the W. R. Wiley Environmental Molecular Sciences Laboratory (EMSL) by JL and FMF. Patchwork spectral processing, database searches, and data analysis were performed by FMF at the Georgia Institute of Technology. EMSL is a national scientific user facility sponsored by the U.S. Department of Energy's Office of Biological and Environmental Research located at Pacific Northwest National Laboratory (PNNL). PNNL is operated for the Department of Energy by Battelle. Research at EMSL was supported by a grant from the Chemical Sciences Division, Office of Basic Energy Sciences of the US Department of Energy. During his stance at the University of Arizona, FMF was supported by an NSF-DBI-0244437 grant to VHW. The authors thank Guilong Cheng for his help in performing protein tryptic digests. 


\section{References}

1. Marko-Varga, G. Proteomics Principles and Challenges. Pure Appl. Chem. 2004, 76, 829-837.

2. Aebersold, R.; Mann, M. Mass Spectrometry-Based Proteomics. Nature 2003, 422, 198-207.

3. Bogdanov, B.; Smith, R. D. Proteomics by FTICR Mass Spectrometry: Top Down and Bottom Up. Mass Spectrom. Rev. 2005, 24, 168-200.

4. Gauthier, J. W.; Trautman, T. R.; Jacobson, D. B.Sustained Off-Resonance Irradiation for Collision-Activated Dissociation Involving Fourier-Transform Mass-Spectrometry-Collision-Activated Dissociation Technique that Emulates Infrared Multiphoton Dissociation.Anal. Chim. Acta2462111991225

5. Shen, Y.; Tolic, N.; Masselon, C.; Pasa-Tolic, L.; Camp, D.; Hixson, K.; Zhao, R.; Anderson, G.; Smith, R. Ultrasensitive Proteomics Using High-efficiency On-Line Micro-SPE-NanoLC-NanoESI MS and MS/MS. Anal. Chem. 2004, 76, 144-154.

6. Marshall, A. G.; Hendrickson, C. L.; Jackson, G. S. Fourier Transform Ion Cyclotron Resonance Mass Spectrometry: A Primer. Mass Spectrom. Rev. 1998, 17, 1-35.

7. Freitas, M. A.; King, E.; Shi, S. D. H. Tool Command Language Automation of the Modular Ion Cyclotron Data Acquisition System (MIDAS) for Data-Dependent Tandem Fourier Transform Ion Cyclotron Resonance Mass Spectrometry. Rapid Commun. Mass Spectrom. 2003, 17, 363-370.

8. Meiring, H.; van der Heeft, E.; ten Hove, G.; de Jong, A. Nanoscale LC-MS(n): Technical Design and Applications to Peptide and Protein Analysis. J. Sep. Sci. 2002, 25, 557-568.

9. Moore, R.; Licklider, L.; Schumann, D.; Lee, T. A. Microscale Electrospray Interface Incorporating a Monolithic, Poly(styrene-divinylbenzene) Support for On-Line Liquid Chromatography Tandem Mass Spectrometry Analysis of Peptides and Proteins. Anal. Chem. 1998, 70, 4879-4884.

10. Wu, S. L.; Jardine, I.; Hancock, W. S.; Karger, B. L. A. New and Sensitive On-Line Liquid Chromatography/Mass Spectrometric Approach for Top-Down Protein Analysis: The Comprehensive Analysis of Human Growth Hormone in an E. coli Lysate Using a Hybrid Linear Ion Trap/Fourier Transform Ion Cyclotron Resonance Mass Spectrometer. Rapid Commun. Mass Spectrom. 2004, 18, 2201-2207.

11. Li, L.; Masselon, C. D.; Anderson, G. A.; Pasa-Tolic, L.; Lee, S.-W.; Shen, Y.; Zhao, R.; Lipton, M. S.; Conrads, T. P.; Tolic, N.; Smith, R. D. High-Throughput Peptide Identification From Protein Digests Using Data-Dependent Multiplexed Tandem FTICR Mass Spectrometry Coupled with Capillary Liquid Chromatography. Anal. Chem. 2001, 73, 3312-3322.

12. Masselon, C.; Anderson, G. A.; Harkewicz, R.; Bruce, J. E.; Pasa-Tolic, L.; Smith, R. D. Accurate Mass Multiplexed Tandem Mass Spectrometry for High-Throughput Polypeptide Identification from Mixtures. Anal. Chem. 2000, 72, 1918-1924.

13. Cooper, H. J.; Hakansson, K.; Marshall, A. G. The Role of Electron Capture Dissociation in Biomolecular Analysis. Mass Spectrom. Rev. 2005, 24, 201-222.

14. Laskin, J.; Futrell, J. H. Collisional Activation of Peptide Ions in FT-ICR Mass Spectrometry. Mass Spectrom. Rev. 2003, 22, 158-181.

15. Laskin, J.; Futrell, J. H. Activation of Large Ions in FT-ICR Mass Spectrometry. Mass Spectrom. Rev. 2005, 24, 135-167.

16. Dunbar, R. C. BIRD (Blackbody Infrared Radiative Dissociation): Evolution, Principles, and Applications. Mass Spectrom. Rev. 2004, 23, 127-158.

17. Tsybin, Y. O.; Hakansson, P.; Budnik, B. A.; Haselmann, K. F.; Kjeldsen, F.; Gorshkov, M.; Zubarev, R. A. Improved Low-Energy Electron Injection Systems for High Rate Electron Capture Dissociation in Fourier Transform Ion Cyclotron Resonance Mass Spectrometry. Rapid Commun. Mass Spectrom. 2001, 15, 1849-1854

18. Zubarev, R. A.; Horn, D. M.; Fridriksson, E. K.; Kelleher, N. L.; Kruger, N. A.; Lewis, M. A.; Carpenter, B. K.; McLafferty, F. W. Electron Capture Dissociation for Structural Characterization of Multiply Charged Protein Cations. Anal. Chem. 2000, 72, 563-573.

19. Little, D. P.; Speir, J. P.; Senko, M. W.; O'Connor, P. B.; McLafferty, F. W. Infrared Multiphoton Dissociation of Large Multiply Charged Ions for Biomolecule Sequencing. Anal. Chem. 1994, 66, 2809-2815.

20. Price, W. D.; Schnier, P. D.; Williams, E. R. Tandem Mass Spectrometry of Large Biomolecule Ions by Blackbody Infrared Radiative Dissociation. Anal. Chem. 1996, 68, 859-866.

21. Schey, K.; Cooks, R. G.; Grix, R.; Woellnik, H. A. Tandem Time-of-Flight Mass Spectrometer for Surface-Induced Dissociation. Int. J. Mass Spectrom. Ion Processes 1987, 77, 49-61.

22. Morris, M. R.; Riederer, D. E.; Winger, B. E.; Cooks, R. G.; Ast, T.; Chidsey, C. E. D. Ion/Surface Collisions at Functionalized Self-Assembled Monolayer Surfaces. Int. J. Mass Spectrom. Ion Processes 1992, 122, 181-217.

23. Grill, V.; Shen, J.; Evans, C.; Cooks, G. Collisions of Ions with Surfaces at Chemically Relevant Energies: Instrumentation and Phenomena. Rev. Sci. Instrum. 2001, 72, 3149-3179.
24. Wieghaus, A.; Schmidt, L.; Popova, A. M.; Komarov, V. V.; Jungclas, H. Grazing Incidence Surface-Induced Dissociation of Protonated Peptides Generated by Matrix-Assisted Laser Desorption/Ionization. Rapid Commun. Mass Spectrom. 2000, 14, 1654-1661.

25. Nikolaev, E. N.; Somogyi, A.; Smith, D. L.; Gu, C.; Wysocki, V. H.; Martin, C. D.; Samuelson, G. L. Implementation of Low-Energy SurfaceInduced Dissociation (eV SID) and High-Energy Collision-Induced Dissociation (keV CID) in a Linear Sector-TOF Hybrid Tandem Mass Spectrometer. Int. J. Mass Spectrom. 2001, 212, 535-551.

26. Gamage, C. M.; Fernandez, F. M.; Kuppannan, K.; Wysocki, V. H. Submicrosecond Surface-Induced Dissociation of Peptide Ions in a MALDI TOF MS. Anal. Chem. 2004, 76, 5080-5091.

27. Dongre, A. R.; Jones, J. L.; Somogyi, A.; Wysocki, V. H. Influence of Peptide Composition, Gas-Phase Basicity, and Chemical Modification on Fragmentation Efficiency: Evidence for the Mobile Proton Model. J. Am. Chem. Soc. 1996, 118, 8365-8374.

28. Zhong, W.; Nikolaev, E. N.; Futrell, J. H.; Wysocki, V. H. Tandem Fourier Transform Mass Spectrometry Studies of Surface-Induced Dissociation of Benzene Monomer and Dimer Ions on a Self-Assembled Fluorinated Alkanethiolate Monolayer Surface. Anal. Chem. 1997, 69, 2496-2503.

29. Chorush, R. A.; Little, D. P.; Beu, S. C.; Wood, T. D.; McLafferty, F. W. Surface-Induced Dissociation of Multiply Protonated Proteins. Anal. Chem. 1995, 67, 1042-1046.

30. Laskin, J.; Denisov, E.; Shukla, A. K.; Barlow, S. E.; Futrell, J. H. Surface-Induced Dissociation in a Fourier Transform Ion Cyclotron Resonance Mass Spectrometer: Instrument Design and Evaluation. Anal. Chem. 2002, 74, 3255-3261.

31. Schlosser, A.; Lehmann, W. D. Patchwork Peptide Sequencing: Extraction of Sequence Information from Accurate Mass Data of Peptide Tandem Mass Spectra Recorded at High Resolution. Proteomics 2002, 2, 524-533.

32. Perkins, D. N.; Pappin, D. J. C.; Creasy, D. M.; Cottrell, J. S. ProbabilityBased Protein Identification by Searching Sequence Databases Using Mass Spectrometry Data. Electrophoresis 1999, 20, 3551-3567.

33. Fernandez, F. M.; Smith, L.; Krishnamoorthy, K.; Yang, X.; Somogyi, A.; Wysocki, V. H. Peptide Sequencing Using a Patchwork Approach and Surface-Induced Dissociation in Sector-TOF and Dual Quadrupole Mass Spectrometers. J. Am. Soc. Mass Spectrom. 2003, 14, 1387-1401.

34. Laskin, J.; Beck, K. M. Hache, J. J.; Futrell, J. H. Surface-Induced Dissociation of Ions Produced by Matrix-Assisted Laser Desorption/ Ionization in a Fourier Transform Ion Cyclotron Resonance Mass Spectrometer. Anal. Chem. 2004, 76, 351-356.

35. Laskin, J.; Futrell, J. H. Energy Transfer in Collisions of Peptide Ions with Surfaces. J. Chem. Phys. 2003, 119, 3413-3420.

36. Laskin, J.; Denisov, E.; Futrell, J. Comparative Study of CollisionInduced and Surface-Induced Dissociation. 2. Fragmentation of Small Alanine-Containing Peptides in FT-ICR MS. J. Phys. Chem. B 2001, 105, 1895-1900.

37. Shaffer, S. A.; Prior, D. C.; Anderson, G. A.; Udseth, H. R.; Smith, R. D. An Ion Funnel Interface for Improved Ion Focusing and Sensitivity Using Electrospray Ionization Mass Spectrometry. Anal. Chem. 1998, 70, 4111-4119.

38. Senko, M. W.; Canterbury, J. D.; Guan, S. H.; Marshall, A. G. A. High-performance Modular Data System for Fourier Transform Ion Cyclotron Resonance Mass Spectrometry. Rapid Commun. Mass Spectrom. 1996, 10, 1839-1844.

39. Frank, A.; Tanner, S.; Bafna, V.; Pevzner, P. Peptide Sequence Tags for Fast Database Search in Mass-spectrometry. J. Proteome. Res. 2005, 4, 1287-1295.

40. Tsaprailis, G.; Nair, H.; Somogyi, A.; Wysocki, V. H.; Zhong, W. Q.; Futrell, J. H.; Summerfield, S. G.; Gaskell, S. J. Influence of Secondary Structure on the Fragmentation of Protonated Peptides. J. Am. Chem. Soc. 1999, 121, 5142-5154

41. Stone, E. G.; Gillig, K. J.; Ruotolo, B. T.; Russell, D. H. Optimization of a Matrix-Assisted Laser Desorption Ionization Ion Mobility SurfaceInduced Dissociation Orthogonal Time-of-Flight Mass Spectrometer: Simultaneous Acquisition of Multiple Correlated MS ${ }^{1}$ and $\mathrm{MS}^{2}$ Spectra. Int. J. Mass Spectrom. 2001, 212, 519-533.

42. Stone, E. Gillig K. I; Ruotolo, B. Fuhrer, K. Gonin, M. Schultz, A. Russell, D. H. Surface-Induced Dissociation on a MALDI-Ion Mobility Orthogonal-Time-of-Flight Mass Spectrometer: Sequencing Peptides from an "In-Solution" Protein Digest. Anal. Chem. 2001, 73, 2233-2238.

43. Laskin, J.; Denisov, E.; Futrell, J. A. Comparative Study of CollisionInduced and Surface-Induced Dissociation. 1. Fragmentation of Protonated Dialanine. J. Am. Chem. Soc. 2000, 122, 9703-9714.

44. Wysocki, V. H.; Tsaprailis, G.; Smith, L. L.; Breci, L. A. Mobile and Localized Protons: A Framework for Understanding Peptide Dissociation. J. Mass Spectrom. 2000, 35, 1399-1406.

45. Harrison, A. G.; Csizmadia, I. G.; Tang, T. H. Structure and Fragmentation of b(2) Ions in Peptide Mass Spectra. J. Am. Soc. Mass Spectrom. 2000, 11, 427-436.

46. Huang, Y. Y.; Triscari, J. M.; Tseng, G. C.; Pasa-Tolic, L.; Lipton, M. S. Smith, R. D.; Wysocki, V. H. Statistical Characterization of the Charge State and Residue Dependence of Low-Energy CID Peptide Dissociation Patterns. Anal. Chem. 2005, 77, 5800-5813. 